\title{
Case report - Hemangioma of the urinary bladder
}

\author{
Seyma Ozkanli ${ }^{1,2, ~ *, ~ B u r c i n ~ G i r g i n ~}{ }^{1}$, Duygu Kosemetin ${ }^{1}$, Ebru Zemheri ${ }^{1}$ \\ ${ }^{1}$ Goztepe Training and Research Hospital, Istanbul Medeniyet University, Department of Pathology, Istanbul - Turkey \\ ${ }^{2}$ Tütüncü Mehmet Efendi Caddesi, Karanfil Sokak, Uğur Apartmanı No:16/3 Göztepe-İstanbul/Turkey
}

\section{Email address:}

seymaozkanli@gmail.com (S. Ozkanli)

\section{To cite this article:}

Seyma Ozkanli, Burcin Girgin, Duygu Kosemetin, Ebru Zemheri. Case Report - Hemangioma of the Urinary Bladder. Science Journal of Clinical Medicine. Vol. 3, No. 1, 2014, pp. 15-16. doi: 10.11648/j.sjcm.20140301.14

\begin{abstract}
Hemangioma of the urinary bladder is a rare and benign tumor which may be present at any age. Among all kinds of bladder tumors, hemangioma of the bladder constitutes just $0.6 \%$ of them. It consists of numerous proliferative capillaries united with thin-walled, expanded blood-filled vessels that are covered by flat endothelial cells. Here, we present a case of a 60 years old man referred to our hospital with macroscopic hematuria and we discuss hemangioma of the bladder that is the diagnosis we determined after the cystoscopic examination.
\end{abstract}

Keywords: Hematuria, Urology, Hemangioma, Bladder

\section{Introduction}

Hemangioma of the urinary bladder is a rare benign tumor and can be present at any age with irritative voiding complaints, abdominal pain, and especially hematuria. We report a case of 60 -year-old male patient referred to our clinic with painless macroscopic hematuria. During the cystoscopic examination, we found out a bluish-red, broad-based, bleeding mass located on the bladder wall. We determined the diagnosis histologically as hemangioma.

\section{Case Report}

A 60-year-old male patient was referred to our hospital with painless macroscopic hematuria lasting 13 days. He was afebrile and did not have any history of trauma or weight loss. He had a smoking history of 50 pack-years. He had not used any anticoagulant and he did not specify any exposure of chemical material. Physical examination did not reveal any syndromic feature as port-wine stain, varicose veins, etc. Blood work-up was within normal range with $13.5 \mathrm{~g} / \mathrm{dl}$ of hemoglobin and $40 \%$ of hematocrit. Any possibility of renal disease was excluded by renal function test. Urea and creatinin were within the normal range (urea: $29 \mathrm{mg} / \mathrm{dL}$, creatinin: $0.98 \mathrm{mg} / \mathrm{dL}$ ). However, urinalysis showed 45 to 50 red blood cells and 2 to 3 white blood cells per high power field. No imaging methods like ultrasonography or tomography was performed. Cystoscopy was planned to rule out bladder tumour. A bluish-red, broad-based, bleeding mass, $0.5 \mathrm{~cm}$ of diameter was located on the left postero-lateral wall of the bladder during cystoscopy. When patient's age and his complaint (macroscopic, painless hematuria) were considered, carcinoma was the first possibility to come to mind. As far as a bluish-red mass was seen, a vascular lesion such as hemangioma or angiosarcoma, was also possible. Transurethral endoscopic resection was performed by urologists. The resection material $0.5 \mathrm{~cm}$ of diameter taken during procedure was examined histologically to ascertain the diagnosis. The lesion and the muscularis propria layer were seen microscopically. We observed a lesion composed of multiple small blood vessels lined by flat endothelial cells without atypia and separated by moderate amounts of fibrous connective tissue (Figure 1). The endothelial cells were positive for CD 31 (Figure 2) and CD 34 (Figure 3). Thus, we diagnosed this unusual case as "hemangioma of the urinary bladder".

\section{Figures}

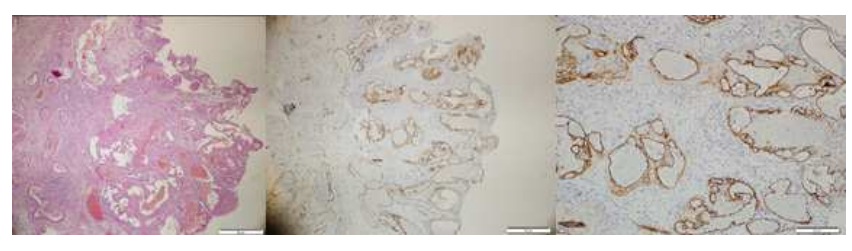

(1)

(2)

(3)

Figure 1. Large dilated vessel proliferation filled with red blod cells $(H \& E$, x40).Surface is eroded.2. CD 31 immunoreactivity in endothelial cells.3. CD 34 immunoreactivity in endothelial cells. 


\section{Discussion}

Generally developed in dermal and epidermal parts of body, mucosal location as urinary bladder is uncommon for heamangioma (1). The lesion arises mostly from a congenital background and may occur at any age but Cheng et al. report in a series comprised of 19 patients with the mean age of 58 at the time of the diagnosis. There is a male predominance; male-to-female ratio is 3,7: 1 (2). Hemangioma of the bladder accounts for only $0.6 \%$ of all bladder tumors (3). Multiple hemangiomas of childhood may be seen in congenital syndromes like Klippel-Trenaunay-Weber and Sturge-Weber, which precipitate their development (4). Hendry and Vinnicombe reviewed a group of patient up to 1971. This group was formed by 32 patients younger than 20 years old. This review exhibited that only 22 patients had diagnosed histologically (1). On cystoscopic examination, generally on the posterior and lateral walls of the bladder, a single blue raised mass can be found. Hemangiomas are commonly small and Cheng et al. showed that most of these lesions are generally $<3 \mathrm{~cm}$.

Hemangioma is histologically classified as cavernous, capillary or arteriovenous (1). The most common type occurring in the bladder is cavernous type. Histologically, these lesions are similar to hemangiomas found at other sites. Hemangioma is composed of numerous proliferatif capillaries admixed with thin-walled, dilated blood-filled vessels lined by flat endothelial cells (4). Angiosarcoma and Kaposi sarcoma are two major entities for hemangioma's differential diagnosis. Cytologic atypia is the most important criteria for distinction (4).

Exuberant granulation tissue and papillary-polypoid cystitis should be considered in differential diagnosis. Moreover, the other entities that must be considered in differential diagnosis are chemotherapy effect, changes secondary to radiation therapy, prior biopsy site, and adenovirus-associated hemorrhagic cystisis. Clinical history is required for a correct diagnosis. Adenovirus-associated hemorrhagic cystisis can be seen in children and the patients with immune-suppression (4).

The presenting symptoms are irritative voiding complaints, abdominal pain and especially hematuria (2). Hemodynamic complications are rarely present (1). These symptoms are undefined and can be present in bladder carcinoma. After all, approximately $20 \%$ of patients being evaluated for gross hematuria will subsequently be diagnosed with bladder cancer (4). When suspected, cystoscopic and radiologic examinations should be done. Cystoscopic view is nonspecific. Only $16 \%$ of cases are suspected clinically (2). For a lesion of mean size, transurethral resection provides a treatment and a diagnosis $(1,2,5)$. Other procedure like laser treatment is also reported as successful (1). The modality changes as the tumor gets larger, partial or total cystectomy may be indicated in such cases $(1,2)$. Recurrences may occur when removal has been incomplete; otherwise surgical result is excellent (6).

\section{References}

[1] Sarıbacak A, Ozkurkccugil C, Ozkan L. Arteriovenous hemangioma of the urinary bladder following intravesical treatment. Urol. J. 2011 Summer; 8 (3): 251-253.

[2] Cheng L, Nascimento AG, Neumann RM, Cheville JC, Ramnani DM, Leibovich BC, Bostwick DG. Hemangioma of the urinary bladder, Cancer 1999; 86:505-13.

[3] Mukai S, Tanaka H, Goto T, Onizuko C, Kamoto T, Kataoka H. Urinary bladder pyogenic granuloma:a case report. J Med. Case Rep. 2012 Jun 12; 6(1):149.

[4] Cheng L, Lopez-Beltran A, Bostwick DG. Bladder Pathology. 2012;140, 437-439.

[5] Tavora F, Montghomery E, Epstein JI. A series of vascular tumor and tumorlike lesions of the bladder. Am J Surg Pathol. 2008 Aug; 32(8): 1213-1219.

[6] Morales A. Haemangioma of the bladder.Postgraduate Medical Journal 1972 February 48;117-118. 